\title{
Severe Periodontitis and Risk for Poor Glycemic Control in Patients with Non- Insulin-Dependent Diabetes Mellitus
}

\author{
George W. Taylor, ${ }^{*}$ Brian A. Burt, ${ }^{\dagger}$ Mark P. Becker,${ }^{\dagger}$ Robert J. Genco,${ }^{\ddagger}$ Marc \\ Shlossman, $\$$ William C. Knowler," and David J. Pettitt"
}

THIS STUDY TESTED THE HYPOTHESIS THAT SEVERE PERIODONTITIS in persons with noninsulin-dependent diabetes mellitus (NIDDM) increases the risk of poor glycemic control. Data from the longitudinal study of residents of the Gila River Indian Community were analyzed for dentate subjects aged 18 to 67 , comprising all those: 1) diagnosed at baseline with NIDDM (at least $200 \mathrm{mg} / \mathrm{dL}$ plasma glucose after a 2-hour oral glucose tolerance test); 2) with baseline glycosylated hemoglobin $\left(\mathrm{HbA}_{\mathrm{l}}\right)$ less than 9\%; and 3) who remained dentate during the 2-year follow-up period. Medical and dental examinations were conducted at 2 -year intervals. Severe periodontitis was specified two ways for separate analyses: 1) as baseline periodontal attachment loss of 6 $\mathrm{mm}$ or more on at least one index tooth; and 2) baseline radiographic bone loss of $50 \%$ or more on at least one tooth. Clinical data for loss of periodontal attachment were available for 80 subjects who had at least one follow-up examination, 9 of whom had two follow-up examinations at 2-year intervals after baseline. Radiographic bone loss data were available for 88 subjects who had at least one follow-up examination, 17 of whom had two follow-up examinations. Poor glycemic control was specified as the presence of $\mathrm{HbA}_{1}$ of $9 \%$ or more at follow-up. To increase the sample size, observations from baseline to second examination and from second to third examinations were combined. To control for non-independence of observations, generalized estimating equations (GEE) were used for regression modeling. Severe periodontitis at baseline was associated with increased risk of poor glycemic control at follow-up. Other statistically significant covariates in the GEE models were: 1) baseline age; 2) level of glycemic control at baseline; 3) having more severe NIDDM at baseline; 4) duration of NIDDM; and 5) smoking at baseline. These results support considering severe periodontitis as a risk factor for poor glycemic control and suggest that physicians treating patients with NIDDM should be alert to the signs of severe periodontitis in managing NIDDM. J Periodontol 1996;67:1085-1093.

Key Words: Periodontitis/complications; diabetes mellitus, non-insulin dependent; hyperglycemia; hypoglycemia; longitudinal studies; epidemiology; models, statistical.

Diabetes mellitus and adult periodontal disease are two relatively common chronic diseases in the United States. Both conditions can produce disability, and clinicians have long assumed these diseases are biologically linked. The presumed link between diabetes mellitus and perio-

\footnotetext{
*University of Michigan School of Dentistry, Ann Arbor, MI.

${ }^{+}$University of Michigan School of Public Health, Ann Arbor, MI.

\#Department of Oral Biology, School of Dental Medicine, State University of New York, Buffalo, NY.

sPrivate Practice, Chandler, AZ.

National Institute of Diabetes, Digestive and Kidney Diseases, Phoenix, AZ.
}

dontitis is considered to stem from an increased susceptibility of people with diabetes to many types of infections, though this hypothesis has been questioned. ${ }^{1,2}$ Other work has suggested that diabetes adversely affects host resistance only to certain infections which influence the endocrinologic-metabolic status of the diabetic patient. Gram-negative anaerobes have been implicated in this latter set of infections, with Bacteroides species among the organisms identified. ${ }^{3-5}$ Adult periodontitis is a bacterial infection in which Gram-negative anaerobes, including Porphyromonas gingivalis and Prevotella intermedia (classified in the genus Bacteroides until 1988 and 1990, 
respectively $\left.{ }^{6.7}\right)$, spirochetes, and occasionally the microaerophilic organism Actinobacillus actinomycetemcomitans, dominate the flora in subgingival bacterial plaque and are considered putative periodontopathogens..$^{8-15}$

Many studies have reported a positive relationship between poor glycemic control and increased occurrence of periodontitis, ${ }^{16-32}$ though a number have also reported no association. ${ }^{33-43}$ These studies vary extensively in their design, conduct, and analyses, and the collective findings from them are inconsistent. No firm conclusions can be drawn from this body of literature.

There is far less research into the converse question, that is, whether periodontal infection contributes to problems with glycemic control. Despite this lack of research evidence, a relationship between the detrimental effects of periodontal infection on metabolic control and the beneficial effects on metabolic control from treating periodontal infections in people with diabetes has long been presumed. ${ }^{44}$ Indeed, this relationship is still cited in current texts of both internal medicine and periodontology ${ }_{4}^{45-47}$ Williams and Mahan $^{48}$ noted reductions in insulin requirements for seven of nine patients after periodontal therapy, an interesting finding that does not appear to have been investigated further. Miller et al., ${ }^{49}$ in a pilot study evaluating the effect of reducing gingival inflammation on glycemic control in nine patients, reported an association between improved periodontal bleeding response and more favorable blood glucose levels. There are no further reports from longitudinal studies or clinical trials that specifically assess the effect of periodontal infection or its treatment on glycemic control in non-insulin-dependent diabetes mellitus (NIDDM).

An opportunity to study this issue came from a longitudinal study among residents of the Gila River Indian Community, the majority of whom are from the Pima tribe, in Sacaton, Ariz. The National Institute of Diabetes, Digestive and Kidney Diseases (NIDDK) has been conducting longitudinal research in this community since 1965 to study non-insulin-dependent diabetes mellitus. ${ }^{50}$ This community has the highest prevalence of NIDDM ever reported-around $50 \%$ of its adult population. ${ }^{51}$ In conjunction with the NIDDK study, a longitudinal project investigating oral health in the Gila River Indian Community included clinical periodontal data collection for 7 years (1982 to 1989). ${ }^{52}$ Previous analyses from these projects, both cross-sectional ${ }^{52-54}$ and longitudinal, ${ }^{55}$ have concluded that periodontitis was more prevalent, more severe, and of higher incidence in Pima Indians with NIDDM than in those without. The purpose of the longitudinal analyses in the present paper is to test the hypothesis that the risk of poor glycemic control is greater in subjects with severe periodontitis than in those who do not have severe periodontitis.

\section{METHODS}

Data for these analyses came from participants of the ongoing NIDDK longitudinal follow-up study and related longitudinal oral health study conducted from 1982 to 1989. Subjects of the present study were of at least half Pima ancestry, aged 18 years or older, and examined approximately every 2 years. The examination included a medical history, physical examination, and review of outpatient and inpatient medical care records. Subjects selected were all dentate persons 1) who were diagnosed as having NIDDM at baseline, defined by plasma glucose concentration $\geq 200 \mathrm{mg} / \mathrm{dL} 2$ hours after a 75 -g oral glucose load; 2) who had good glycemic control, as shown by baseline glycosylated hemoglobin $\left(\mathrm{HbA}_{1}\right)$ values less than $9 \%$ measured by electrophoresis ${ }^{56.57}$; and 3 ) who did not become edentulous during the 2-year follow-up period. Venous blood was obtained 2 hours following ingestion of $75 \mathrm{~g}$ of carbohydrate. II Plasma glucose was determined by the modified Hoffman method, using the $\mathrm{Au}-$ toanalyzer." The outcome variable, poor glycemic control, was specified as a dichotomous response anc defined as the occurrence of glycosylated hemoglobin $\left(\mathrm{HbA}_{1}\right)$ of $9 \%$ or more at follow-up.

All clinical oral examinations were conducted by one of two trained and calibrated examiners who, at the time of examination, did not know the diabetes status of examined subjects. Assessment of clinical loss of periodontal attachment was made using the six index teeth or their substitutes as described by Ramfjord..$^{58}$ Panoramic radiographs were used to assess interproximal bone loss throughout the dentition, with measurements made using a modified Schei technique. ${ }^{52}$ All panoramic radiographs were made by a single technician and read by a single examiner, both of whom were unaware of the diabetes status of the subjects. Examiner reliability was assessed by analyses of duplicate clinical periodontal examinations and radiographic evaluations; both intra- and interexaminer reliability were good..$^{52}$ Severe periodontitis is difficult to define, especially when definitions mix the measures of past and current disease. For this study, severe periodontitis was specified in two different ways for separate analyses: 1) baseline radiographic bone loss of $50 \%$ or more for at least one tooth (WBS50); and 2) baseline maximum loss of periodontal attachment of $6 \mathrm{~mm}$ or more for at least one index tooth (MAXAL6). This approach of using two separate measures of destructive periodontitis was chosen to maximize the yield of information, because the number of subjects in the data set with radiographs differed from the number with clinical loss of periodontal attachment (LPA) measurements. It also was an attempt to test the consistency of an effect using

"Glucola, Ames Co., Elkhart, IN; Dexcola, Custom Laboratories, Baltimore, MD.

"Technicon Instruments Corp., Tarrytown, NY. 
these separate measures of past disease. In selecting the specifications for severe periodontitis, several alternative specifications were evaluated, varying the minimum number of affected teeth/sites required in the definition (i.e., 2 or more vs. less than $2, \ldots, 6$ or more vs. less than 6 ) in bivariate analyses of the association between severe periodontitis and poor glycemic control at follow-up. In each case there was a tendency for the odds ratio to increase as the minimum number of affected teeth/sites required for the severe disease category increased. In any scheme used to develop a dichotomous specification for those with and without severe periodontitis, some subjects would likely be misclassified. The definitions selected for these analyses tend to misclassify some subjects who truly do not have severe periodontitis as having severe disease. However, this misclassification is non-differential; i.e., the classification errors for periodontal status are independent of category of follow-up glycemic control status. The consequence of this non-differential misclassification is to potentially attenuate the effects of severe periodontal disease on the outcome, thus biasing estimated odds ratios toward the null. Hence, this most conservative specification was chosen because it would have made it more difficult to reject the null hypothesis.

Several additional behavioral, medical, dental, and demographic variables were included to further characterize subjects' baseline status. Self-reported alcohol consumption and smoking were obtained from subject interviews. Additional variables from the clinical medical examination included obesity, defined as body mass index $>27$ $\mathrm{kg} / \mathrm{m}^{2}$; retinopathy, defined as any proliferative retinopathy or preretinal hemorrhage or at least one microaneurism or hemorrhage detected using direct opthalmoscopy; and systolic blood pressure, measured at the first Korotkoff sound in the right arm with the subject in the supine position near the end of the medical examination. Medical laboratory tests provided information for nephropathy, defined as having a urine albumin to urine creatinine ratio of at least $30 \mathrm{mg} / \mathrm{g}^{59,60} ; \mathrm{HbA}_{1}$; NIDDM severity, assessed during an oral glucose tolerance test by the plasma glucose concentration drawn 2 hours after the 75-g glucose load, with "less severe" defined as no history of insulin use and fasting plasma glucose less than $300 \mathrm{mg} / \mathrm{dL}$ and "more severe" defined as a history of ever using insulin or plasma glucose $\geq 300 \mathrm{mg} / \mathrm{dL}$; and coronary artery disease, determined by presence of an abnormality on resting EKG according to the Whitehall criteria. ${ }^{61} \mathrm{~A}$ review of medical records provided information on insulin use and oral hypoglycemic use, distinguishing those subjects who ever used these agents prior to or at baseline (insulin use, ever or oral hypoglycemic use, ever) from those who were current users at baseline (current insulin use or current oral hypoglycemic use). Further information obtained from the dental examination included number of teeth. Demographic variables included age and gender.
This group of baseline covariates was assessed for confounding and effect modification in the analyses. Age, duration of NIDDM, $\mathrm{HbA}_{1}$, number of teeth, and systolic blood pressure were used in models as continuous covariates. Indicator variables were defined for alcohol consumption ( $\geq 3$ drinks per day), gender, insulin use, oral hypoglycemic use, nephropathy, coronary artery disease, retinopathy, NIDDM severity, and smoking in the year preceeding baseline.

The data used for these analyses consisted of observations from baseline to second examination and from the second to third examination for subjects who still met the baseline entry requirements. Clinical data for loss of periodontal attachment were available for 80 individuals who had at least one follow-up examination, 9 of whom had two follow-up examinations at 2-year intervals after baseline. Radiographic bone loss data were available for 88 individuals who had at least one follow-up examination, 17 of whom had two follow-up examinations. The term "subject" in these analyses refers to an observation in the combined data sets. These combined data maximized the number of observations, thus allowing for maximal precision in estimating effects.

Contingency table analyses were used to examine data adequacy and patterns suggesting possible confounding or effect modification. Multivariate logistic regression models were used to estimate the effect of severe periodontitis on risk for poor glycemic control. These regression models were developed in stages. First, using a forward stepwise selection procedure, ${ }^{* *}$ all variables considered to be confounders or effect modifiers were in cluded in a model with a severe periodontitis variable (WBS50 or MAXAL6) forced to remain in each model considered. In addition to testing for main effects, firstorder interaction terms were tested for relations between baseline age and all the covariates, between baseline periodontal status and several selected covariates, and between baseline glycemic control and all other main effects. Quadratic terms were tested for all continuous covariates.

This initial selection stage resulted in two candidate models, i.e., one for each of the severe periodontitis variables. Next, each of the variables that had been previously eliminated in the stepwise selection procedure was separately retested in these two final candidate models and retained if it attained a level of significance with $P$ value $<0.05$. Finally, to control for non-independence of observations, these candidate models were retested using generalized estimating equations (GEE), ${ }^{62}$ and the final two models were accepted from the GEE estimation procedure. Regression models were tested for goodness-offit $^{63}$ before final acceptance, and conclusions on whether

**PROC LOGISTIC, SAS Institute, Inc., Cary, NC. 
Table 1. Baseline Descriptors for Subjects Who Had NIDDM and Radiographic Bone Loss Data and Were Included in the Generalized Estimating Equation Analysis of the Incidence of Poor Glycemic Control* (Percentage of Subjects by Follow-Up HbA, Status Shown in Parentheses)

\begin{tabular}{|c|c|c|c|c|}
\hline & \multicolumn{4}{|c|}{ Follow-Up $\mathrm{HbA}_{1}$} \\
\hline & \multicolumn{2}{|c|}{ WBS50 Data } & \multicolumn{2}{|c|}{ MAXAL6 Data } \\
\hline & $<9 \%$ & $9 \%$ or more & $<9 \%$ & $9 \%$ or more \\
\hline No. of observations* & $84(80.0)$ & $21(20.0)$ & $72(80.9)$ & $17(19.1)$ \\
\hline No. of subjects & $67(76.1)$ & $21(23.9)$ & $63(78.7)$ & $17(21.2)$ \\
\hline No. with second exam ${ }^{+}$ & $14(82.4)$ & $3(17.6)$ & $8(88.9)$ & $1(11.1)$ \\
\hline Gender: Male & $26(83.9)$ & $5(16.1)$ & $24(88.9)$ & $3(11.1)$ \\
\hline Female & $58(78.4)$ & $16(21.6)$ & $48(77.4)$ & $14(22.6)$ \\
\hline Age (range, in years) & $18.0-67.4$ & $26.7-60.5$ & $18.0-65.9$ & $29.5-60.5$ \\
\hline \multicolumn{5}{|l|}{ Age categories } \\
\hline $18-34$ & $25(81.0)$ & $6(19.0)$ & $25(89.0)$ & $3(11.0)$ \\
\hline $35-49$ & $29(70.7)$ & $12(29.3)$ & $27(73.0)$ & $10(27.0)$ \\
\hline $50-64$ & $27(90.0)$ & $3(10.0)$ & $19(82.6)$ & $4(17.4)$ \\
\hline $65+$ & $3(100)$ & 0 & $1(100)$ & 0 \\
\hline Number of teeth (range) & $3-28$ & $17-28$ & $11-28$ & $21-28$ \\
\hline Number of teeth (median) & 26 & 26 & 26 & 26 \\
\hline Duration (median years) & 4.7 & 2.9 & 4.5 & 3.2 \\
\hline $\mathrm{HbA}_{1}($ median $\%)$ & 7.0 & 7.9 & 7.0 & 7.8 \\
\hline \multicolumn{5}{|l|}{ WBS50 } \\
\hline$<50 \%$ & $47(83.9)$ & $9(16.1)$ & $\mathrm{NA}^{\ddagger}$ & NA \\
\hline $50 \%+$ & $37(75.5)$ & $12(24.5)$ & NA & NA \\
\hline \multicolumn{5}{|l|}{ MAXAL6 } \\
\hline$<6 \mathrm{~mm}$ & NA & NA & $55(88.7)$ & $7(11.3)$ \\
\hline $6 \mathrm{~mm}+$ & NA & NA & $17(63.0)$ & $10(37.0)$ \\
\hline
\end{tabular}

*Includes all observations from baseline to second examination and second examination to third examination. Includes only subjects who had two follow-up examinations after baseline.

NA $=$ not applicable.

to accept or reject the hypothesis were based on the total of all the analyses.

\section{RESULTS}

Table 1 shows the distribution of baseline characteristics, specifying baseline worst bone score (WBS50) or maximum loss of periodontal attachment (MAXAL6), respectively, as the principal exposure. The number is larger for subjects using WBS50 data than for those with MAXAL6 data (105 versus 89 ) because several subjects who had radiographs taken were at risk for subacute bacterial endocarditis and hence were excluded from periodontal probing examination. A higher proportion of subjects with severe periodontitis (WBS50 or MAXAL6) than those without had poorer glycemic control at follow-up (i.e., $24 \%$ vs. $16 \%$ for WBS50 and $37 \%$ vs. $11 \%$ for MAXAL6). There were higher proportions of subjects who were female and higher proportions in the 35 to 49 years age category who developed poor glycemic control at follow-up. Baseline values were lower for median duration of NIDDM and higher for median glycosylated hemoglobin for subjects who had poor glycemic control at follow-up.

Bivariate relationships between glycemic control at follow-up and subject characteristics at baseline are presented in Table 2. The WBS50 and MAXAL6 data sets were consistent in the proportions of subjects having poor glycemic control at follow-up in 10 of the 13 covariate subtables of Table 2 (seven had higher proportions with the specific baseline characteristic: more severe NIDDM, ever used insulin, currently using oral hypoglycemic drug, ever used oral hypoglycemic drug, obesity, smoking, using alcohol; three had smaller proportions: retinopathy, nephropathy, and coronary artery disease). Only NIDDM duration and current insulin use had proportions in opposite directions. Several of the bivariate associations in the table have sparse data in at least one cell.

Table 2 gives a good overview of relationships between key variables, but also may be misleading when potential confounding exists, and when other indirect relationships exist but are not clearly visible. Multivariate models were therefore estimated to evaluate the results of simultaneously considering the effects of severe periodontitis and all other covariates. Table 3 summarizes the results of the final, most parsimonious GEE models analyzing the association between severe periodontitis at baseline and incident poor glycemic control, using WBS50 and MAXAL6 as separate specifications for baseline severe periodontitis. Both models suggest that severe periodontitis at baseline has a significant influence on poor glycemic control at follow-up, when controlled for the other covariates. Additional covariates in the WBS50 model that were significantly associated with poor glycemic control at follow-up included baseline values for age, glycosylated he- 
Table 2. Cumulative Incidence of Poor Glycemic Control at Follow-Up, by Baseline Status for Selected Subject Characteristics*

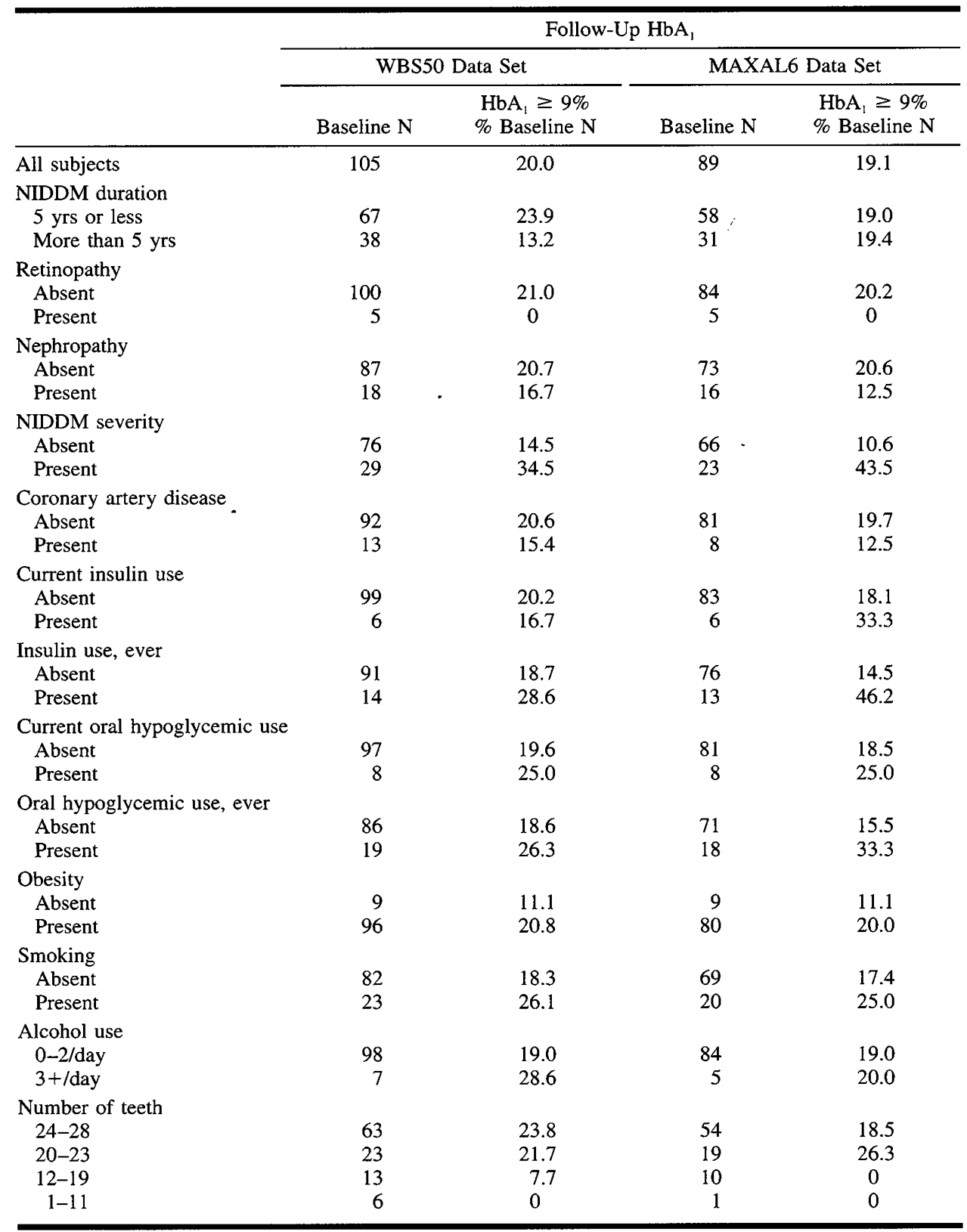

*Includes observations used in GEE analysis from baseline to second examination and second examination to third examination.

moglobin, and an interaction between age and periodontal status. Baseline values for smoking and severity and duration of NIDDM were additional covariates in the MAXAL6 model. Table 4 presents the estimated age-specific odds ratios for poor glycemic control at follow-up, detailing a decreasing effect of severe periodontitis as age increases, as suggested by the baseline age-periodontal status interaction term in the WBS50 model.

\section{DISCUSSION}

The results from this analysis strongly suggest that severe periodontitis at baseline increases risk for poorer glycem- ic control at follow-up. Both the WBS50 and MAXAL6 models are consistent in estimating positive coefficients for the two alternative indicators of severe periodontitis. It is particularly noteworthy that the effect of baseline severe periodontitis on glycemic control at follow-up holds, even when controlled for the effects of baseline level of $\mathrm{HbA}_{1}$ in the WBS50 model (odds ratio $=1.94$, $95 \%$ confidence interval $=1.08,3.48$ ) and in the MAXAL6 model (the coefficient for $\mathrm{HbA}_{1}$ is not shown because its $P$-value was $>0.05$ ), and for baseline severity of NIDDM in the MAXAL6 model (OR $=17.78,95 \%$ 
Table 3. Summary Table of Coefficient Estimates from GEE Modeling Procedures for Incidence of Poor Metabolic Control

\begin{tabular}{|c|c|c|c|c|c|c|c|c|}
\hline & \multicolumn{4}{|c|}{$\begin{array}{l}\text { WBS50 Data* } \\
N=105\end{array}$} & \multicolumn{4}{|c|}{$\begin{array}{c}\text { MAXAL6 Data } \\
\quad \mathrm{N}=89\end{array}$} \\
\hline & $\begin{array}{l}\text { Coeff. } \\
\text { Estm. }\end{array}$ & $\begin{array}{l}\text { Std. } \\
\text { Error }\end{array}$ & $P$-Value ${ }^{\hat{f}}$ & Odds Ratios & $\begin{array}{l}\text { Coeff. } \\
\text { Estm. }\end{array}$ & $\begin{array}{l}\text { Std. } \\
\text { Error }\end{array}$ & $P$-Value $*$ & Odds Ratio \\
\hline \multicolumn{9}{|l|}{ Main Effects } \\
\hline Intercept & 6.726 & 2.343 & .0041 & & -2.700 & 0.065 & $<.0001$ & \\
\hline WBS50/MAXAL6 & 5.558 & 2.500 & .0264 & see Table 4 & 1.821 & 0.719 & .0114 & $6.2(1.5,25.3)$ \\
\hline Agell (in years) & 0.007 & 0.027 & .7795 & see Table 4 & & & & \\
\hline $\mathrm{HbA}_{1}^{\prime \prime}(\%)$ & 0.660 & 0.299 & .0271 & $1.9(1.1,3.5)$ & & & & \\
\hline Smokingll & & & & & 1.573 & 0.763 & .0394 & $4.8(1.1,21.5)$ \\
\hline NIDDM severity" & & & & & 2.878 & 0.701 & .0001 & $17.8(4.5,70: 2)$ \\
\hline Duration" (in years) & & & & & -0.193 & 0.068 & .0045 & $0.8(0.7,0.9)$ \\
\hline \multicolumn{9}{|l|}{ Interaction } \\
\hline Age.WBS".ศ & -0.118 & 0.054 & .0366 & see Table 4 & & & & \\
\hline
\end{tabular}

*Generalized estimating equations model of incidénce of poor glycemic control using baseline severe periodontitis defined as baseline radiographic bone loss of 50\% or more (WBS50). The data set for this analysis was created by including observations from baseline to second biennial examination and observations from second biennial examination to third biennial examination.

"Generalized estimating equations model of incidence of poor glycemic control using baseline severe periodontitis defined as baseline maximum loss of periodontal attachment of $6 \mathrm{~mm}$ or more (MAXAL6). The data set for this analysis was created by including observations from baseline to second biennial examination and observations from second biennial examination to third biennial examination.

${ }^{4} P$-value of the standard normal variable, $z$.

$\$$ Odds ratio with $95 \%$ confidence limits in parentheses.

"Variables found to have $P$-value $>0.05$ were excluded from the model and do not have estimates for the coefficient, standard error, $P$-value, or odds ratio presented in this table.

"A term to specify the interaction between age and WBS50.

Table 4. Severe Periodontitis-Associated, Age-Specific, Odds Ratios for Poor Glycemic Control at Follow-Up, Using the WBS50 Model

\begin{tabular}{lccc}
\hline & & \multicolumn{2}{c}{$95 \%$ Confidence Limits } \\
\cline { 3 - 4 } Baseline Age & Odds Ratio & Lower Limit & Upper Limit \\
\hline 25 & 13.57 & 1.74 & 105.99 \\
30 & 7.52 & 1.48 & 38.20 \\
35 & 4.17 & 1.17 & 14.88 \\
40 & 2.31 & 0.79 & 6.79 \\
45 & 1.28 & 0.42 & 3.95 \\
50 & 0.71 & 0.18 & 2.85 \\
\hline
\end{tabular}

$\mathrm{CI}=4.50,70.24)$. These two covariates would be expected to have a strong influence on the degree of glycemic control at follow-up and possibly to overshadow the estimated effects of other variables in their respective statistical models. The different covariate patterns of the two models may be due to the relatively small sample sizes, different $\mathrm{N}$, slightly different distributions of subjects for the covariates, and different dimensions of the two measures of severe periodontitis.

Although the two models assessing the effects of severe periodontitis have different covariate patterns, they are complementary in providing insight into other factors to be considered in evaluating the effect of severe periodontitis on the risk of poor glycemic control. The WBS50 model suggests that the effect of severe periodontitis at baseline decreases as age increases. This finding is illustrated in Table 4, where the odds ratios for subjects with severe periodontitis $($ WBS50 $=1$ ) decrease with increasing age. These odds ratios reflect the direction and statistical significance of the term for the interaction between baseline age and periodontal status (AGE.WBS) in the WBS50 model shown in Table 3. This interaction must be interpreted cautiously because, as shown in Table 1 , there are sparse data in the 50 to 64 and 65 and older age categories and there was only one subject younger than 20 years old. The MAXAL6 model suggests that baseline status as a smoker increases risk for poor glycemic control at follow-up $(\mathrm{OR}=4.82,95 \% \mathrm{CI}=1.08$, 21.51). This could be a direct effect or it could be that people who smoke are less health conscious than nonsmokers, and may therefore be less concerned with maintaining good glycemic control. The MAXAL6 model also suggests that duration of NIDDM is inversely related to having poorer glycemic control at follow-up (OR $=0.82$, $95 \% \mathrm{CI}=0.72,0.94)$. This result contrasts with the data in Table 2, where there is essentially no difference for duration of NIDDM in the proportion of subjects having poor glycemic control at follow-up in the MAXAL6 data set, while a higher proportion of subjects with shorter duration of NIDDM have poor control at follow-up in the WBS50 data set. This apparent paradox is not disturbing when one considers that the magnitude and direction of bivariate associations, as presented in Table 2 , can change in multivariate models where the effects of several variables are controlled simultaneously. A greater incidence of poor glycemic control in diabetic subjects with shorter duration of diabetes would be consistent with the hypothesis that hyperglycemia worsens linearly with time, but at different rates in different people. Under this hypothesis, those with rapidly worsening hyperglycemia would 
already have $\mathrm{HbA}_{1}>9 \%$ if their baseline examination occurred when they already had a long duration of diabetes, and thus they would have been excluded from this analysis. On the other hand, the only subjects with long duration at their baseline examination with $\mathrm{HbA}_{1}<9 \%$ would be those with a relatively slow (or no) worsening of hyperglycemia with time. Such subjects would be more likely to remain in good control during the follow-up period.

The analyses in this report were confined to subjects with NIDDM. The dependent variable, incidence of poor glycemic control, was given a dichotomous specification; poor control was defined as the occurrence of glycosylated hemoglobin of $9 \%$ or more. This value was chosen because it is near the $\mathrm{HbA}_{1}$ antimode in this population. ${ }^{64}$ Recognizing that choice of a cut-point results in an arbitrary classification by categorizing the continuous values for glycosylated. hemoglobin, separate analyses were performed (results not shown) using cut-points of $8 \%$ and $10 \%$ as well as a continuous specification for glycosylated hemoglobin at both baseline and follow-up. In those auxiliary analyses, the estimated effect for severe periodontitis remained significant and consistent with the effects presented here. A potential limitation in these analyses is choosing an arbitrary cut-point for the $\mathrm{HbA}_{1}$. By dichotomizing follow-up $\mathrm{HbA}_{1}$, subjects with values slightly above or below the cut-point would tend to be similar with respect to glycemic control status, although classified as having a different response in the analysis. This imposed dichotomous classification of good versus poor control could weaken the power to detect an effect for severe periodontitis by assigning subjects with similar follow-up glycemic control characteristics to different response categories. However, the results of these analyses permitted rejecting the null hypothesis, thus strengthening support for an effect of severe periodontitis on glycemic control.

As described earlier, severe periodontitis was specified in two ways: 1) baseline radiographic bone loss of $50 \%$ or more (WBS50); and 2) baseline maximum loss of periodontal attachment of $6 \mathrm{~mm}$ or more (MAXAL6). Using the two different ways of measuring periodontitis and conducting separate analyses provided increased rigor in assessing an effect for baseline periodontitis. These measures, while correlated, ${ }^{65}$ still detect somewhat different dimensions of severe periodontitis. Because measurement error is unavoidable and different for each of the two measurement techniques used, the likelihood of the effect of severe periodontitis on glycemic control found being attributed to spurious association is diminished.

While there is no general acceptance of definitions for severe or moderate periodontitis, it seems reasonable to define a level of attachment loss or pocketing which represents a point beyond which the function of the tooth is compromised or the risk of tooth loss is great. ${ }^{66}$ One mod- el sees moderate periodontitis as that degree of bone loss, periodontal attachment loss, or pocketing that is detectable clinically or radiographically but is not severe enough to threaten the loss of teeth. ${ }^{67}$ Severe periodontitis, in this model, is that degree of periodontitis sufficiently severe to cause or threaten the loss of teeth. Operationally, $4 \mathrm{~mm}$ loss of periodontal attachment has been suggested as the minimum for diagnosis of destructive periodontitis $^{68}$ and $6 \mathrm{~mm}$ or more for severe periodontitis. This definition is satisfactory from an epidemiological perspective because it allows sufficient discrimination in a population for risk factor research. ${ }^{67}$ Additionally, radiographic bone loss of $50 \%$ or more, or LPA of $6 \mathrm{~mm}$ or more, is often considered by clinicians as points beyond which the function of a tooth is compromised or risk of tooth loss increased.

This study supports earlier clinical impressions and provides epidemiological evidence that severe periodontitis is a risk factor for poor glycemic control, but the mechanisms explaining this relationship have not yet been clarified. Relationships between insulin resistance and active inflammatory connective tissue diseases, ${ }^{69,70}$ other clinical diseases, ${ }^{71,72}$ and acute infection ${ }^{73,74}$ have been reported however. Further, tumor necrosis factor- $\alpha$ and other cytokines found to be associated with destructive periodontitis have been reported to interfere with insulin's actions and lead to metabolic alterations during infection. ${ }^{75,76}$ Though not tested, these relationships may also be important when there is severe periodontal infection in patients with NIDDM.

The analyses presented here support considering severe periodontitis as a risk factor for poor glycemic control. They suggest the possibility that prevention and management of periodontitis may be important to successful management of NIDDM and that physicians treating patients with NIDDM should be alert to the signs of severe periodontitis. Future studies should test this relationship in other populations, evaluate the effects of treating periodontitis on metabolic control in patients with diabetes, and address molecular mechanisms that would explain this association.

\section{Acknowledgments}

This study was supported by the Michigan Diabetes Research and Training Center and by NIDR grants DE06514 and DE07157. We wish to acknowledge Dr. Lynn Budding for his consultation, scholarly contributions, and field work in helping to collect the oral health data; Ms. Ana Cabrera-Arevalo for assistance in data management and computer programming; Dr. Irving Liebow (deceased) for reading the EKGs; Dr. Peter H. Bennett for his advice and consultation; and the members and leaders of the Gila River Indian Community for generously participating in and encouraging the study. 


\section{REFERENCES}

1. Kaslow RA. Infections in diabetics. In: Harris MI, ed. Diabetes in America. Washington, DC: Government Printing Office; 1985. NIH publication $85-1468$.

2. Wilson RM. Infection and diabetes mellitus. In: Pickup JC, Williams W, eds. Textbook of Diabetes. London: Blackwell Scientific Publications; 1991:813-818.

3. Rayfield EJ, Ault MJ, Keusch GT, Brothers MJ, Nechemias C, Smith $\mathrm{H}$. Infection and diabetes: The case for glucose control. Am J Med 1982;72:439-450.

4. Wheat JL. Infection in diabetes mellitus. Diabetes Care 1980;3:187197.

5. Lewis RP, Sutter VL, Finegold SM. Bone infections involving anaerobic bacteria. Medicine 1978;57:279-305.

6. Shah HN, Collins MD. Proposal for reclassification of Bacteroides asaccharolyticus, Bacteroides gingivalis, and Bacteroides endodontalis in a new genus, Porphyromonas. Int J Syst Bacteriol 1988;38: $128-131$.

7. Shah HN, Collins MD. Prevotella, a new genus to include Bacteroides melaninogenicus and related species formerly classified in the genus Bacteroides. Int J Syst Bacteriol 1990;40:205-208.

8. Dzink JL, Socransky SS, Haffajee AD. The predominant cultivable microbiota of active and inactive lesions of destructive periodontal diseases. J Clin Periodontol 1988;15:316-323.

9. Loesche WJ, Syed SA, Schmidt E, Morrison EC. Bacterial profiles of subgingival plaques in periodontitis. $J$ Periodontol 1985;56:447456.

10. Slots J, Genco RJ. Black-pigmented Bacteroides species, Capnocytophaga species, and Actinobacillus actinomycetemcomitans in human periodontal disease: Virulence factors in colonization, survival and tissue destruction. J Dent Res 1984;63:412-421.

11. Moore WEC. Microbiology of periodontal disease. $J$ Periodont Res 1987;22:335-341.

12. Zambon JJ. Actinobacillus actinomycetemcomitans in human periodontal disease. J Clin Periodontol 1985;12:1-20.

13. Kornman KS, Robertson PB. Clinical and microbiological evaluation of therapy for juvenile periodontitis. J Periodontol 1985;56: 443-446.

14. Slots J, Hafstrom C, Rosling B, Dahlén G. Detection of Actinobacillus actinomycetemcomitans and Bacteroides gingivalis in subgingival smears by the indirect fluorescent-antibody technique. $J$ Periodont Res 1985;20:613-620.

15. Genco RJ, Zambon JJ, Christersson LA. The origin of periodontal infections. Adv Dent Res 1988;2:245-259.

16. Tervonen T, Oliver RC. Long-term control of diabetes mellitus and periodontitis. J Clin Periodontol 1993;20:431-435.

17. Seppala B, Seppala M, Ainamo J. A longitudinal study on insulindependent diabetes mellitus and periodontal disease. J Clin Periodontol 1993;20:161-165.

18. Cutler CW, Eke P, Arnold RR, Van Dyke TE. Defective neutrophil function in an insulin-dependent diabetes mellitus patient. A case report. J Periodontol 1991;62:394-401.

19. Oliver RC, Tervonen T. Periodontitis and tooth loss: Comparing diabetics with the general population. J Am Dent Assoc 1993;124:7176.

20. Unal T, Firatli E, Sivas A, Meric $\mathrm{H}, \mathrm{Oz} \mathrm{H}$. Fructosamine as a possible monitoring parameter in non-insulin-dependent diabetes mellitus patients with periodontal disease. J Periodontol 1993;64:191194.

21. Mendieta C, Reeve CM. Periodontal manifestations of systemic disease and management of patients with systemic disease. Curr Opin Periodontol 1993;1:18-27.

22. Gislen G, Nilsson KO, Matsson L. Gingival inflammation in diabetic children related to degree of metabolic control. Acta Odontol Scand 1980;38:241-246.
23. Safkan-Seppala B, Ainamo J. Periodontal conditions in non-insulindependent diabetes mellitus. J Clin Periodontol 1992;19:24-29.

24. Ainamo J, Lahtinen A, Uitto VJ. Rapid periodontal destruction in adult humans with poorly controlled diabetes. A report of 2 cases. $J$ Clin Periodontol 1990;17:22-28.

25. Gusberti FA, Syed SA, Bacon G, Grossman N, Loesche WJ. Puberty gingivitis in insulin-dependent diabetic children. $J$ Periodontol 1983;54:714-720.

26. Löe H. Periodontal disease. The sixth complication of diabetes mellitus. Diabetes Care 1993;16:329-334.

27. Ervasti T, Knuuttila M, Pohjamo L, Haukipuro K. Relation between control of diabetes and gingival bleeding. J Periodontol 1985;56: 154-157.

28. Galea H. The dental caries and periodontal disease experience of patients with early-onset insulin-dependent diabetes. Int Dent $J$ 1986;36:219-224.

29. Harrison R, Bowen WH. Periodontal health, dental caries, and metabolic control in insulin-dependent diabetic children and adolescents. Pediatr Dent 1987;9:283-286.

30. Kjellman O, Henriksson C-O, Berghagen N, Andersson B. Oral conditions in 105 subjects with insulin-treated diabetes mellitus. Swed Dent $J$ 1970;63:99-110.

31. Finestone AJ, Boorujy SR. Diabetes mellitus and periodontal disease. Diabetes 1967;16:336-340.

32. Tervonen T, Knuuttila M. Relation of diabetes control to periodontal pocketing and alveolar bone level. Oral Surg Oral Med Oral Pathol 1986;61:346-349.

33. Bacic M, Plancak D, Granic M. CPITN assessment of periodontal disease in diabetic patients. $J$ Periodontol 1988;59:816-822.

34. Hove KA, Stallard RE. Diabetes and the periodontal patient. J Periodontol 1970;41:713-718.

35. Wolf J. Dental and periodontal conditions in diabetes mellitus. A clinical and radiographic study. Proc Finn Dent Soc 1977;(4-6 suppl):1-56.

36. Albrecht M, Banoczy J, Tamas G. Dental and oral symptoms of diabetes mellitus. Community Dent Oral Epidemiol 1988;16:378380.

37. Barnett ML, Baker RL, Yancey JM, MacMillan DR, Kotoyan M. Absence of periodontitis in a population of insulin-dependent diabetes mellitus (IDDM) patients. J Periodontol 1984;55:402-405.

38. Hayden P, Buckley LA. Diabetes mellitus and periodontal disease in an Irish population. $J$ Periodont Res 1989;24:298-302.

39. Nichols C, Laster LL, Bodak-Gyovai LZ. Diabetes mellitus and periodontal disease. J Periodontol 1978;49:85-88.

40. Rylander H, Ramberg P, Blohme G, Lindhe J. Prevalence of periodontal disease in young diabetics. J Clin Periodontol 1987;14:3843.

41. Sandholm L, Swanljung O, Rytomaa I, Kaprio EA, Maenpaa J. Periodontal status of Finnish adolescents with insulin-dependent diabetes mellitus. $J$ Clin Periodontol 1989;16:617-620.

42. Sandholm L, Swanljung O, Rytomaa I, Kaprio EA, Maenpaa J. Morphotypes of the subgingival microflora in diabetic adolescents in Finland. J Periodontol 1989;60:526-528.

43. Sastrowijoto SH, Hillemans P, van Steenbergen TJM, Abraham-Inpijn I, de Graaff J. Periodontal condition and microbiology of healthy and diseased periodontal pockets in type 1 diabetes mellitus patients. J Clin Periodontol 1989;16:316-322.

44. Williams JB. Diabetic periodontoclasia. J Am Dent Assoc 1928;15: 523-529.

45. Trieger N, Boguslaw B. The mouth in diabetes. In: Rifkin H, Porte D, eds. Diabetes Mellitus Theory and Practice. New York: Elsevier; 1990:850-855.

46. Terezhalmy GT. Dental correlations: diabetes mellitus. In: Rose LF, Kaye D, eds. Internal Medicine for Dentistry. St. Louis: The CV Mosby Company; 1990:1153-1155.

47. Genco RJ, Wilson ME, DeNardin E. Periodontal complications and 
neutrophil abnormalities. In: Genco RJ, Goldman HM, Cohen DW, eds. Contemporary Periodontics. St. Louis: The CV Mosby Company; 1990:203-220.

48. Williams RC, Mahan CJ. Periodontal disease and diabetes in young adults. JAMA 1960;172:776-778.

49. Miller LS, Manwell MA, Newbold D, et al. The relationship between reduction in periodontal inflammation and diabetes control: A report of 9 cases. J Periodontol 1992;63:843-848.

50. Knowler WC, Bennett PH, Hamman RF, Miller M. Diabetes incidence and prevalence in Pima Indians: A 19-fold greater incidence than in Rochester, Minnesota. Am J Epidemiol 1978;108:497-505.

51. Knowler WC, Pettitt DJ, Savage PJ, Bennett PH. Diabetes incidence in Pima Indians: Contributions of obesity and parental diabetes. Am $J$ Epidemiol 1981;113:144-156.

52. Shlossman M, Knowler WC, Pettitt DJ, Genco RJ. Type 2 diabetes mellitus and periodontal disease. J Am Dent Assoc 1990;121:532536.

53. Emrich LJ, Shlossman M, Genco RJ. Periodontal disease in noninsulin-dependent diabetes mellitus. J Periodontol 1991;62:123130.

54. Zambon JJ, Reynolds H, Fisher JG, Shlossman M, Dunford R, Genco RJ. Microbiological and immunological studies of adult periodontitis in patients with non-insulin-dependent diabetes mellitus. $J$ Periodontol 1988;59:23-31.

55. Nelson RG, Shlossman M, Budding LM, et al. Periodontal disease and NIDDM in Pima Indians. Diabetes Care 1990;13:836-840.

56. Menard L, Dempsey ME, Blankstein LA, Aleyassine H, Wacks M, Soeldner JS. Quantitative determination of glycosylated hemoglobin $A_{1}$ by agar gel electrophoresis. Clin Chem 1980;26:1598-1602.

57. Nathan DM, Dunn BS, Francis TB. Two commercial methods evaluated for eliminating the labile fraction from the assay for glycated hemoglobin (glycohemoglobin). Clin Chem 1984;30:109-110.

58. Ramfjord SP. Indices for prevalence and incidence of periodontal disease. J Periodontol 1959;30:51-59.

59. Nelson RG, Kunzelman CL, Pettitt DJ, Saad MF, Bennett PH, Knowler WC. Albuminuria in Type 2 (non-insulin-dependent) diabetes mellitus and impaired glucose tolerance in Pima Indians. Diabetologia 1989;32:870-876.

60. Nelson RG, Knowler WC, Pettitt DJ, Saad MF, Charles MA, Bennett PH. Assessment of risk of overt nephropathy in diabetic patients from albumin excretion in untimed urine specimens. Arch Intern Med 1991;151:1761-1765.

61. Fuller JH, McCartney P, Jarrett RJ, et al. Hyperglycaemia and coronary heart disease: The Whitehall study. J Chron Dis 1979;32:721728 .

62. Zeger SL, Liang K-Y. Longitudinal data analysis for discrete and continuous outcomes. Biometrics 1986;42:121-130.
63. Hosmer DW, Lemeshow S. Applied Logistic Regression. New York: John Wiley \& Sons; 1989:135-175.

64. McCance DR, Hanson RL, Charles M-A, et al. Comparison of tests for glycated haemoglobin and fasting and two hour plasma glucose concentrations as diagnostic methods for diabetes. BMJ 1994;308: $1323-1328$

65. Papapanou PN, Wennstrom JL. A 10-year retrospective study of periodontal disease progression. Clinical characteristics of subjects with pronounced and minimal disease development. $J$ Clin Periodontol 1990;17:78-84.

66. Johnson NW, Griffiths GS, Wilton JMA, et al. Detection of highrisk groups and individuals for periodontal diseases. Evidence for the existence of high-risk groups and individuals and approaches to their detection. J Clin Periodontol 1988;15:276-282.

67. Burt BA, Eklund SA. Dentistry, Dental Practice, and the Community. 4th ed. Philadelphia: WB Saunders Company; 1992:74-77.

68. Burt BA. The distribution of periodontitis in the industrialized countries: In: Johnson NW, ed. Risk Markers for Oral Diseases. Cambridge: Cambridge University Press; 1991;3:9-26.

69. Hallgren R, Lundquist G. Elevated serum levels of pancreatic polypeptide are related to impaired glucose handling in inflammatory states. Scand J Gastroenterol 1983;18:561-564.

70. Svenson KL, Lundquist G, Wide L, Hallgren R. Impaired glucose handling in active rheumatoid arthritis: Relationship to the secretion of insulin and counter-regulatory hormones. Metabolism 1987;36: 940-943.

71. Beck-Nielsen H. Clinical disorders of insulin resistance. In: Alberti KGMM, Defronzo RA, Keen H, Zimmet P, eds. International Textbook of Diabetes Mellitus. New York: John Wiley \& Sons; 1992: 531-568.

72. Beisel WR. Metabolic response to infection. Ann Rev Med 1975;26: 9-20.

73. Sammalkorpi $\mathrm{K}$. Glucose intolerance in acute infections. $J$ Intern Med 1989;225:15-19.

74. Drobny EC, Abramson EC, Baumann G. Insulin receptors in acute infection: A study of factors conferring insulin resistance. $J$ Clin Endocrinol Metab 1984;58:710-716.

75. Hotamisligil GS, Shargill NS, Spiegelman BM. Adipose expression of tumor necrosis factor-a: Direct role in obesity-linked insulin resistance. Science 1993;259:87-91.

76. Flier JS. An overview of insulin resistance. In: Moller DE, ed. Insulin Resistance. New York: John Wiley \& Sons; 1993:1-8.

Send reprint requests to: Dr. George W. Taylor, Department of Cariology, Restorative Sciences, and Endodontics, University of Michigan School of Dentistry, 1011 N. University, Ann Arbor, MI 48109-1078. E-mail: gwt@umich.edu 